\title{
An Empirical Test on Character of Indifference Curve of Cross-Layer Goods Under Condition of Low Income
}

\author{
Yaozhong Chang \\ Institute of Industrial Economics Chinese Academy of Social Sciences \\ Beijing, China \\ yzhchang@263.net
}

\begin{abstract}
In Goods' indifference curve, income expansion path represents optimized consumption bundle under different income level, the character of which under low income has research gaps. By econometric method of Chow test for predictive failure, consumption payouts of three need layers for four income grades in towns in Tibet are analyzed. Statistics description and econometric result indicate that under condition of low consumption expenditure per capita, goods belonging to lower need layer will be developed earlier than goods belonging to higher need layer for the former's higher priority. This result shows that under condition of low income, higher layer goods toward which income expansion path is curved may increase much more slowly than that of lower layer goods with rise of total payout.
\end{abstract}

Keywords-indifference curve; consumption bundle; income expansion path; Hierarchy of needs

\section{INTRODUCTION}

According to microeconomic theory, the set of all consumption bundles that are indifferent to each other is called an indifference curve. Indifference curve owns convexity which means it is curved toward origin and of diminishing marginal rates of substitution. If all prices are fixed, with income increasing, income expansion path may be beeline (A: proportion of different goods' quantities remaining constant), curved toward one goods (B: this goods' quantity increases faster than the other's) or curved backward toward one goods (C: this goods' quantity increases but the other's quantity decreases) as shown in Fig.1 [1].

Maslow proposed that within every person there is a hierarchy of five needs from view angle of psychology. He indicated that after each need is substantially satisfied, the next need becomes dominant [2]. Maslow argued that if all needs are all unsatisfied, person will be wholly controlled by physiological need, after which is satisfied needs belonging to higher layer will appear immediately [3]. According to Maslow's view, the forementioned proposition in microeconomics should be modified by adding condition of a sufficient quantity of money expenditure. That means if income decreases to be small enough, lower layer need would be in preference and difficult to be substituted by higher layer need. After income increase to be large enough, higher layer need will become dominant need with high increase speed.
The divergence in consumption choice between above two opinions needs verification by empirical test. Data source of consumption payout of residents in towns in Tibet in China from 1992 to 2010 is used, and Chow test for predictive failure on communication payout (need in Layer 3) of four income-grade residents and other comparable data is done. Statistics description and test result show that in case of low income, lower layer need develops in preference, and corresponding character of indifference curve is obviously different from those in Fig.1.
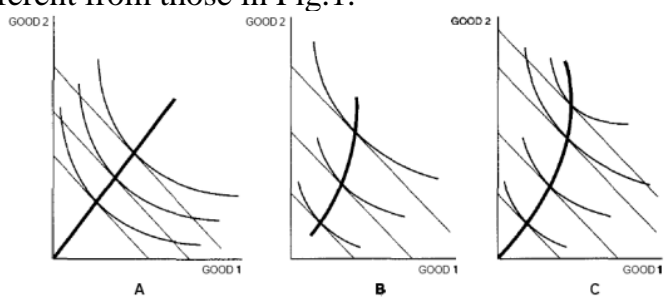

Figure 1. Three types of income expansion path

\section{ECONOMETRIC MODEL BUILDING}

\section{A. Variable Definition}

Maslow's hierarchy of needs theory indicated that need can be divided to five layers, i.e. physiological needs, safety needs, social needs, esteem needs and self-actualization needs. Here, Goods 1, 2 and 3 belong to the former three kinds of needs respectively. Consumption payout per capita is taken as measurement of income per capita.

i) Explanatory variable: y (consumption payout per capita)

ii) Explained variable: $x 1$ (payout of Goods 1 per capita), x2 (payout of Goods 2 per capita), x3 (payout of Goods 3 per capita).

\section{B. Data Selection}

In data selection, below aspects are taken into consideration. i) Reasonable period and district of statistics data should be selected to meet required economic level for easily observing cross-layer transition of dominant need. ii) For convenience of comparison among need layers, payout item should be representative and could be easily differentiated from other items. iii) For convenience of comparison within one layer, one item should not be substituted by another entirely and should be commonly used in different groups and districts. This means one payout item 
should not occur only in some groups and districts because of different partialities. For example, medical care belongs to safety needs, is different from other layers' needs, could not be easily substituted by garment and residence within one need layer and is needed by everyone. According to above considerations, data of payout per capita in consumption from lowest-income grade to middle-income grade in town in Tibet in China from 1992 to 2010 are adopted from Tibet Statistics Yearbooks 1993 to 2011.

1) Goods 1: Grain and oil; Meat, poultry, eggs and aquatic products

2) Goods 2: Garments; Residence; Medical care

3) Goods 3: Communications

Among Goods 1 to 3, communications fee is major item to be tested, and other items are comparison ones. Garments, residence and medical care own characters of physiological needs, but they also fulfill safety needs. Then they are put in Goods 2. Goods i payout below represents the sum of payouts of items in Goods $i$ (marked by xi), in which $i$ is equal to 1,2 or 3 . All payout values are deflated by deflator provided in official website of International Monetary Fund. All deflated payout values are listed in Fig. 2 to 3.

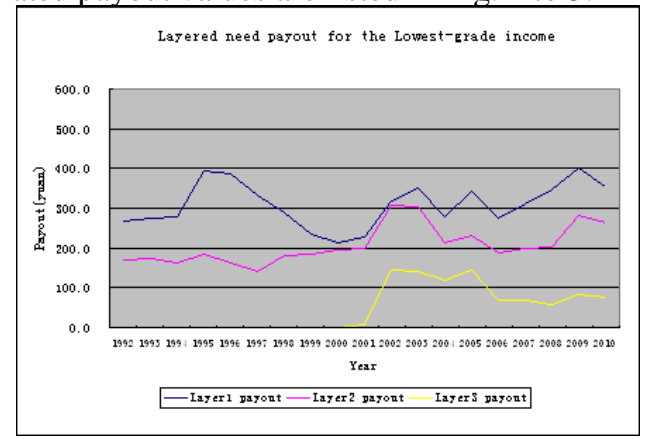

Figure 2. Goods 1-3 payouts for lowest-income grade

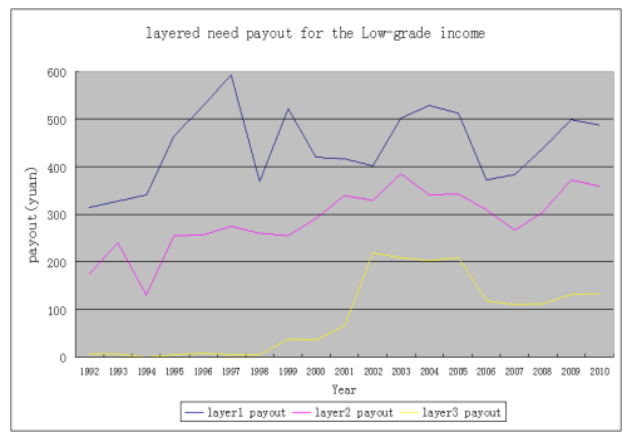

Figure 3. Goods 1-3 payouts for low-income grade

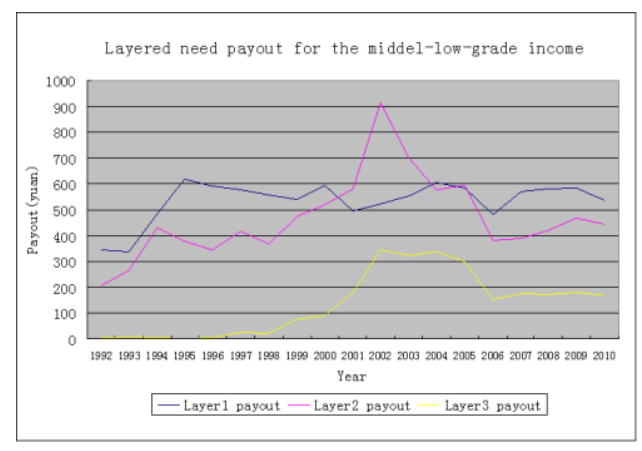

Figure 4. Goods 1-3 payouts for middle-low-income grade

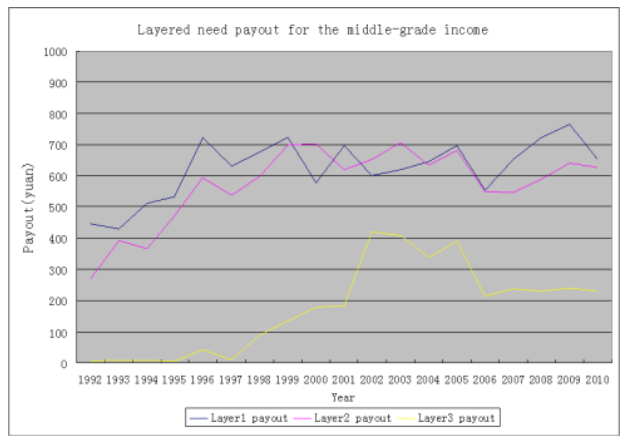

Figure 5. Goods 1-3 payouts for middle-income grade

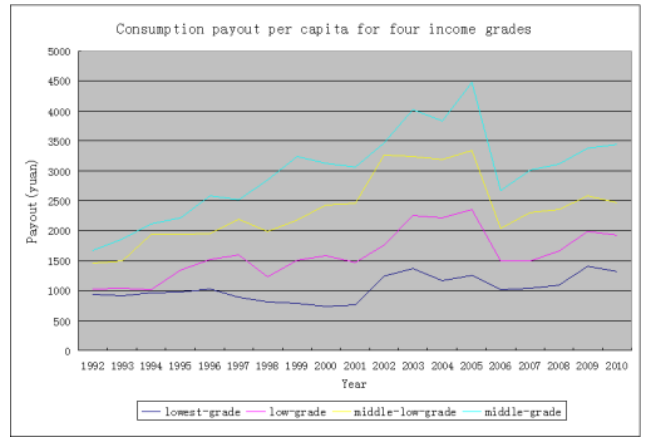

Figure 6. Consumption payout per capita for four income grades

\section{Statistics Description and Econometrics Parameter}

According to payout fluctuation, turning years with structural change for communication payout of four income grades from lowest-income grade to middle-income grade are roughly identified to be 2002, 1999, 1997 and 1996. Statistics description before and after turning years and of entire period is listed in Table I. As shown in Table I, compared with Goods 1 and 2, before and after turning year, Good 3 payout owns extremely huge differences in average values and standard deviation. Here we call period before turning year $\mathrm{n} 1$ phase and period after turning year $\mathrm{n} 2$ phase respectively. For four income grades in Goods 3, average values in $n 1$ phase are only about 0.1 to 3 percent of those in $\mathrm{n} 2$ phase, and standard deviation in $\mathrm{n} 1$ phase are only about 1 
to 5 percent of those in $\mathrm{n} 2$ phase. But for Goods 1 and 2 and consumption payout per capita, the percentages are basically above $50 \%$. Following income grade's variance from high to low and corresponding consumption payout's variance from high to low, the turning years of four income grades occur from early to late. If it is assumed that constant prices keep unchanged or stable for Goods 1 to 3 , the statistics description support conclusions of significant structural change in turning years.

TABLE I. TABLE I STATISTICS DESCRIPTION OF GOODS EXPENDITURE FOR FOUR INCOME GRADES

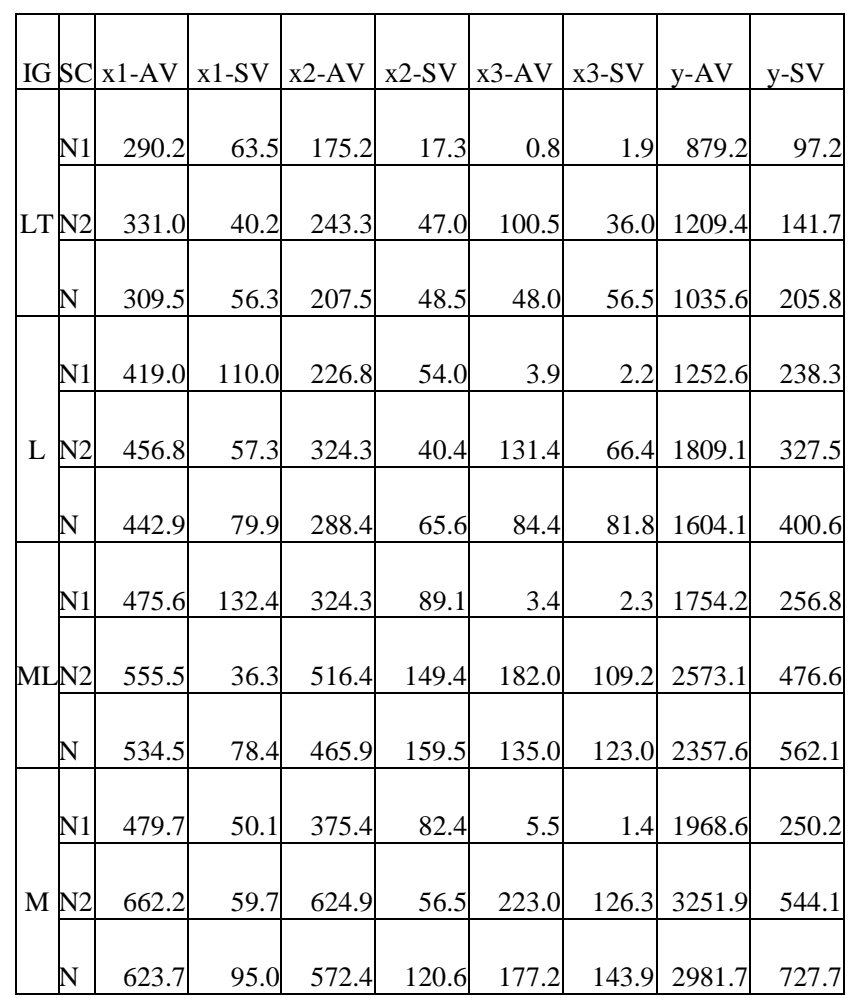

Note: SC, IG, AV, SV, LT, L, ML, M are abbreviations of structural change subsection, income grade, average value, standard deviation, Lowest-income grade, Low-income grade, Middle-lowincome grade and Middle-income grade respectively. N1, N2 and N represents subsection before turning year, subsection after turning year and entire period. The same below.

\section{ECONOMETRIC RESULT AND ANALYSIS}

According to above turning years for communication payout, econometric test by Chow test for predictive failure is done. For comparison, middle-income grade payout on communication is also used as comparison data in other income grades' test. Consumption payout per capita of one income grade and one Goods' payout of this grade are taken as explanatory variable and explained variable respectively for periods of $n 1, n 2$ and N. Residuals gotten by OLS and their square values are used in Chow test with results in Table II.
TABLE II. TEST RESUlT OF CHOW TEST

\begin{tabular}{|c|c|c|c|c|}
\hline $\begin{array}{c}\mathrm{IG} \\
(\mathrm{n} 1 \& \mathrm{n} 2)\end{array}$ & Index & $\begin{array}{c}\mathrm{F} \\
\text { value }\end{array}$ & $\begin{array}{l}\text { Signifi- } \\
\text { cance }\end{array}$ & Parameter \\
\hline \multirow{4}{*}{$\begin{array}{c}\mathrm{LT} \\
\mathrm{n} 1=10 \\
\mathrm{n} 2=9\end{array}$} & $\mathrm{X} 3$ & 543.51 & $99 \%$ & \multirow{2}{*}{$\begin{array}{c}\text { numerator } 9.00 \\
\text { denominator } 8.00\end{array}$} \\
\hline & $\mathrm{X} 1$ & 1.15 & no & \\
\hline & $\mathrm{X} 2$ & 6.66 & no & $\mathrm{F}(5 \%) \quad 3.39$ \\
\hline & M X3 & 4.53 & no & $\mathrm{F}(1 \%) \quad 5.91$ \\
\hline \multirow{4}{*}{$\begin{array}{c}\mathrm{L} \\
\mathrm{n} 1=7 \\
\mathrm{n} 2=12\end{array}$} & X3 & 563.98 & $99 \%$ & \multirow{2}{*}{$\begin{array}{l}\text { numerator } 12.00 \\
\text { denominator } 5.00\end{array}$} \\
\hline & $\mathrm{X} 1$ & 7.46 & no & \\
\hline & $\mathrm{X} 2$ & 0.72 & no & \multirow{2}{*}{$\begin{array}{ll}\mathrm{F}(5 \%) & 4.68 \\
\mathrm{~F}(1 \%) & 9.89 \\
\end{array}$} \\
\hline & M X3 & 11.97 & no & \\
\hline \multirow{4}{*}{$\begin{array}{c}\text { ML } \\
\mathrm{n} 1=5 \\
\mathrm{n} 2=14\end{array}$} & $\mathrm{X} 3$ & 421.65 & $99 \%$ & \multirow{4}{*}{$\begin{array}{lc}\text { numerator } & 14.00 \\
\text { denominator } & 3.00 \\
\mathrm{~F}(5 \%) & 8.71 \\
\mathrm{~F}(1 \%) & 26.92 \\
\end{array}$} \\
\hline & $\mathrm{X} 1$ & 1.39 & no & \\
\hline & $\mathrm{X} 2$ & 4.20 & no & \\
\hline & M X3 & 38.55 & $99 \%$ & \\
\hline \multirow{3}{*}{$\begin{array}{c}M \\
\mathrm{n} 1=4 \\
\mathrm{n} 2=15\end{array}$} & $\mathrm{X} 3$ & 1670.03 & $99 \%$ & \multirow{3}{*}{$\begin{array}{cc}\text { numerator } & 15.00 \\
\text { denominator } & 2.00 \\
\mathrm{~F}(5 \%) & 19.4 \\
\mathrm{~F}(1 \%) & 99.4\end{array}$} \\
\hline & $\mathrm{X} 1$ & 8.49 & no & \\
\hline & $\mathrm{X} 2$ & 1.41 & no & \\
\hline
\end{tabular}

Note: In the fifth column, "Parameter" represents parameters in $\mathrm{F}$ test of Chow prediction test; $\mathrm{F}(5 \%)$ and $\mathrm{F}(1 \%)$ represent percentile points in significances of $5 \%$ or $1 \%$ respectively in $\mathrm{F}$ statistics test. Numerator and denominator represent degrees of freedom for $\mathrm{F}$ test's numerator and denominator. "M X3" means X3 of middle-income grade.

Chow test indicates following results. i) Within each income grade, extremely huge structural change occurs in Goods 3 payouts, but almost no significant change in Goods 1 and 2 payouts. ii) In the turning year of lowest-income grade's Goods 3 payout, no structural change takes place for middle-income grade's Goods 3 payout. In turning years of Goods 3 payouts for low-income grade and middle-lowincome grade, though Good 3 payout for middle-income grade owns $\mathrm{F}$ values some higher than $\mathrm{F}$ percentile point of $1 \%$ in $\mathrm{n} 1$ of 7 and 5 because of its own structural change in n1 of 4, its structural change is far less than those of Goods 3 payouts for low-income grade and middle-low-income grade. Above analysis result shows that with assumption of unchanged or stable constant prices of all goods, low consumption expenditure per capita leads to very significant structural change.

\section{CONCLUSION}

Statistics description and empirical test show following conclusions. i) While consumption payout per capita becomes low, higher layer needs' payouts experiences great structural change. ii) Within the same income grade, in turning year of higher layer need payout, lower layer need payouts have become stable in structures. Among different income grades, turning years appear from early to late along with income grades from high to low. iii) For higher layer need payout, compared with average value and standard deviation after turning year, those before turning year seem to be tiny enough to be neglected. If Good 2 is assumed to belong to lower layer need and Good 1 is assumed to belong to higher layer, their indifference curve and income expansion path are shown in Fig. 7. If income is low and quantity of Good 2 is lower than some value (e.g. T), quantity of Good 2 increase following rise of income, but 
that of Good 1 is of almost no increase. If income becomes big and quantity of Good 2 is higher than T, quantity of Good 1 starts to increase obviously, even faster than Good 2, as shown in Fig.7. This character is very different from forementioned character that quantity of Good toward which the income expansion path is curved has faster increasing speed.

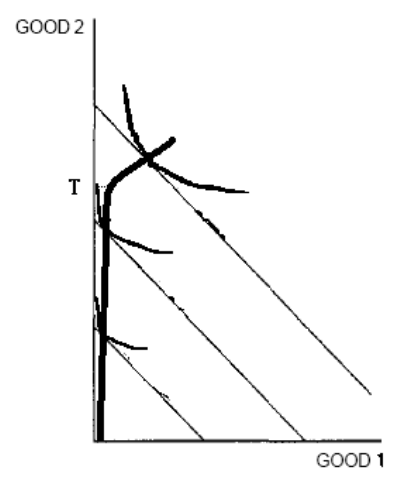

Figure 7. Income expansion path of this case
Above conclusions prove that under low expenditure level, money will be spent in lower layer needs in preference and higher layer needs will be restrained. Consequently, under low income, quantity of Goods toward which income expansion path is curved may increase much slower than that of the other Goods if the former's need layer is higher than the latter's.

\section{REFERENCES}

[1] H.-R. Varian, "Microeconomic analysis (Third edition)", New York: W. W. Norton \& Company, Inc. 1992.

[2] S.-P. Robbins and D.-A. DeCenzo, "Fundamentals of management", 6th Edition, Beijing: China Renmin University Press, 2008.

[3] A.-H. Maslow, "Motivation and personality", Beijing: Huaxia Press, 1987. 